\title{
Presentación
}

La historia tiene, entre muchos otros, el cometido de poner al descubierto cómo se relacionan los seres humanos entre sí y en contextos y momentos determinados, bien sean estos tiempos de coyuntura y transición, bien de aconteceres cotidianos. La originalidad del trabajo que recuperamos del acervo de la Revista radica en la perspectiva que elige para visitar de nuevo la trayectoria del magisterio mexicano, desde una concepción diferente del tiempo, un tiempo múltiple, la historia de las mentalidades, que entra en contacto con una diversidad de ciencias para explicar los procesos históricos y genera un lugar de encuentro para exigencias metodológicas opuestas a las que dispone a dialogar. La utilidad de este enfoque radica en que, al revisar las condiciones políticas, económicas y sociales a la par que las actitudes mentales de los sujetos del tiempo en examen, es posible encontrar el sustrato de otras en plena vigencia en momentos distintos, incluido el presente, lo que resulta imprescindible en periodos como el que vivimos, cuando la colisión de posturas ante la reforma educativa de 2013, pone otra vez de manifiesto imaginarios opuestos acerca de la educación y el magisterio entre los docentes, la ciudadanía y las autoridades del país.

Luego de repasar las condiciones del profesorado mexicano en el periodo que visita, y de evocar a los docentes cuyo descontento les induciría a participar en el movimiento revolucionario de 1910, la autora concluye que la distancia entre el diseño de política pública en las cúpulas del poder y la realidad de las escuelas impidió el avance de las normativas y generó la actitud contestataria y la sublevación de los que atendieron el llamado al combate y se instalaron en la disidencia hasta nuestros días.

Como cualquier revisión histórica, la que sigue produce un efecto refrescante en el análisis de la situación actual desde todos los puntos de vista, pero sobre todo a la hora de pensar en la educación como el hecho que es, de responsabilidad compartida, y como la promesa de que esta generaría mejores condiciones para los miles de ciudadanos que viven en pobreza, carecen de 
una vida digna y de las oportunidades que les brindaría la educación. Preocupa sobre todo el hecho de que, cualquiera que sea el imaginario de las partes confrontadas sobre la educación de calidad que requerimos, esta no ha producido la conciencia crítica necesaria para asumir y manejar el disenso, la pluralidad; para sentarse a escuchar a todos los implicados con la especialización interdisciplinaria propia de las comunidades educativas; tampoco para integrar colectividades dialógicas que establezcan vínculos creativos entre, justamente, educación, democracia y ciudadanía.

Acaso oír y tomar en cuenta a todos los sectores que se han manifestado públicamente sobre el acontecer en el ámbito de la educación nacional durante los últimos meses, el profesorado y sus agrupaciones, importantes grupos de académicos e investigadores educativos, empresarios, funcionarios públicos y ciudadanos permitiera actuar, como en la historia de las mentalidades, sin poner límites ni uniformidad al método del diálogo para integrar los intereses de todos al conjunto y flexibilizar las posiciones en medio de la coyuntura.

Esto sería en especial relevante en uno de los puntos más críticos de la reforma, la Ley del Servicio Profesional Docente, cuyo énfasis, al parecer social, excesivo en la evaluación unilateral de la normativa, ha excluido otras formas también contempladas en esta ley, pero que promueven una total integración de los miembros de las comunidades escolares en el análisis y la evaluación de todos los factores que inciden en la acción educativa y en la búsqueda consensada de alternativas de mejora y solución.

Existen observaciones muy esclarecedoras y entrañables de experiencias de autoevaluación, coevaluación y heteroevaluación que han generado trayectos de automejora en los colectivos docentes de cerca de un millar de escuelas en el país, con los responsables directos de los procesos y los vínculos socioafectivos que se tejen en y en torno a las escuelas y en las aulas, los docentes, peritos fiables del conjunto de factores que realmente influyen en el aprendizaje de sus estudiantes. El efecto solidario que esta evaluación compartida generó entre los participantes ha sido ampliamente reportado en las páginas de esta revista. 


\section{Maestras y maestros en el tiempo. Una mirada desde la historia*}

\section{Teachers through time. A historical perspective}

\begin{abstract}
RESUMEN
Desde la perspectiva de la historia de las mentalidades y del análisis del discurso, este trabajo presenta la trayectoria del profesorado mexicano durante el porfiriato, la Revolución y el periodo postrevolucionario comprendido entre 1920 y 1940, para establecer un contraste entre el imaginario del maestro mexicano y su realidad cotidiana. Para ello muestra cómo el imaginario irá cambiando de acuerdo con el escenario político, económico y social para luego valerse del recurso de la historia oral, por medio de entrevistas a maestras y maestros, que no necesariamente muestra los cambios imaginados. Con ello rebasa una visión estrecha de la historia, no solo en términos temporales sino también en la profundidad y en el ámbito de la comprensión de la situación actual de las maestras y maestros mexicanos.
\end{abstract}

Palabras clave: historia de las mentalidades, análisis del discurso, profesorado mexicano

Luz Elena Galván Lafarga**

\begin{abstract}
This paper presents the trajectories of Mexican teachers during the porfiriato, the revolution and the post-revolutionary period between 1920 and 1940 from the perspective of the history of mentalities and discourse analysis, in order to establish a contrast between the imaginary of the Mexican teacher and their everyday reality. The evolution of this imaginary through political, economic and social contexts will be presented, and then contrasted with oral history from interviews with teachers. This approach transcends a narrow vision of history, not only in temporary terms but also in terms of depth and understanding of the current situation of Mexican teachers.
\end{abstract}

Key words: history of mentalities, discourse analysis, Mexican teachers

\section{PRENTACIÓN}

Un gran historiador francés de nuestros días, Jacques Le Goff, nos recuerda que "el tiempo de la historia, sobre todo después de los trabajos de Fernand Braudel, ya no es el tiempo uniforme y lineal; en cambio, es un tiempo múltiple, irregular y socializado" (Le Goff y Santoni, 1994: 45).

En este artículo, partiré de esta idea del tiempo múltiple, con el fin de entrelazar los diferentes momentos en que se construye el imaginario del maestro mexicano. Imaginario que irá cam-

\footnotetext{
"Trabajo aparecido originalmente en Revista Latinoamericana de Estudios Educativos, vol. vol. XXVI, núm. 2, 1996, pp. 165-191.

"*entro de Investigaciones y Estudios Superiores en Antropología Social (CIESAS.)
} 
biando de acuerdo con el escenario político, económico y social en el que se desarrolle cada uno de ellos.

Iniciaré con un primer escenario que se desenvuelve durante el porfiriato y la Revolución, para después pasar al escenario del periodo postrevolucionario, comprendido entre 1920 y 1940.

Para su elaboración, he utilizado documentos de la "Colección Porfirio Díaz", del Archivo Histórico de la Secretaría de Educación Pública, y de la Colección Latinoamericana Nettie Lee Benson, que se encuentra en la Biblioteca de la Universidad de Texas, en Austin, principalmente. También incluiré el recurso de la historia oral, por medio de entrevistas a maestras y maestros, además de bibliografía complementaria.

\section{EL ESCENARIO PORFIRISTA Y REVOLUCIONARIO}

Corría el año de 1876 y el México decimonónico contaba con un flamante presidente: Porfirio Díaz. Este hombre había sido formado dentro de las ideas de los liberales de su tiempo, donde la educación tenía un importante papel en el discurso educativo.

$\mathrm{Al}$ igual que otros políticos de su época, Díaz se dio a la enorme tarea de tratar de instruir a un pueblo analfabeto. La educación, así, se presentaba como una panacea, como un elemento que permitiría el progreso de la nación.

Varias eran las leyes en favor de la educación que se habían dictado hasta entonces, sin grandes resultados. El problema económico, que cruzaba por todos los aspectos de la vida diaria de la nación, no había hecho una excepción hacia la educación. Y así, a pesar de leyes y decretos, todo quedaba en buenas intenciones, pero en la realidad faltaba mucho por hacer.

Es en este escenario político, económico y social, donde hace su aparición un importante actor: el maestro. Su figura se perfila desde las épocas prehispánica y colonial, sin embargo, es hacia la segunda mitad del siglo XIX cuando aparece con más fuerza.

Durante la primera mitad del siglo XIX encontramos que la profesión de maestro tenía poca aceptación social, además de que sus salarios eran muy bajos. No había suficientes fondos, y cuando los había, no se destinaban a la instrucción pública. 
Otro problema era su deficiente preparación académica, que se trató de remediar mediante el establecimiento de escuelas Normales. Las primeras, todas situadas en provincia, tuvieron corta vida. Las de mediados de siglo, todavía muy escasas, no lograron preparar a todos los maestros que el país necesitaba. En un principio, las Normales solamente procuraron que el futuro maestro dominara bien las materias que quería enseñar, y como si fuera un oficio, practicaba al lado de un maestro experimentado. Las Normales que se encuentran mencionadas en leyes y decretos de la época son, de hecho, escuelas de primeras letras, donde hacían sus prácticas los aspirantes a maestro, sin dárseles ninguna materia pedagógica. La introducción de estos estudios fue posterior.

Entre los estados donde se fundaron las primeras escuelas Normales, las cuales en varias ocasiones pronto desaparecieron, tenemos: Zacatecas, estado que establece la primera Normal en 1826 y luego otra en 1832; San Luis Potosí que en 1849 fundó la Escuela Normal para Profesores y en 1868 para Señoritas; Jalisco, también en 1849, fundó su Normal; Guanajuato, que en 1853 estableció una Escuela Normal para Profesores, y en 1870 para Señoritas; Durango, en 1875, fundó una Escuela Normal para Varones; Nuevo León, en 1870, fundó la Escuela Normal para Profesores y en 1892 para Señoritas; Sinaloa, en 1873, estableció una Escuela Normal Mixta; y Sonora, en 1847, una Escuela Normal para Varones y en 1875 una Escuela Normal Mixta. Hay que mencionar también la Normal Lancasteriana que abrió sus puertas en 1823, pero tuvo efímera vida por falta de alumnos. Otras más se fundaron a partir de 1880 (cfr. Galván, 1980, cuadro y Staples, 1992: 87 y 88).

Toda esta situación hacía que en este escenario de la primera mitad del siglo XIX, el imaginario del maestro no gozara de prestigio alguno, ni fuera tomado en cuenta por la política oficial. Más bien, este imaginario se va a ir construyendo a partir de que el Estado se hace cargo de la educación pública, durante la República Restaurada y, posteriormente, durante el porfiriato. Es entonces cuando, dentro del discurso oficial, el maestro va a tener un papel muy importante.

Teórica y metodológicamente he considerado el imaginario como una de las categorías que atraviesan a la llamada "Nueva Historia" y que permite asomarse a la historia de las mentalidades. 
Evelyne Patlagean expresa que cada cultura, y por tanto cada sociedad, tiene sus imaginarios (Patlagean, 1988:302).

Debido a que uno de los testigos del imaginario es el discurso, únicamente lo trataré desde este punto de vista. En ningún momento pretendo ubicarlo dentro del psicoanálisis. Más bien, lo que presentaré será un análisis de estos dos niveles: por un lado, el discurso, donde se descubre el concepto de imaginario, y por otro, la realidad, la vida cotidiana de muchas maestras y muchos maestros mexicanos en el tiempo.

En este primer escenario del porfiriato, encontramos que el Estado mexicano había asignado a los maestros la tarea de "...cambiar la faz de la República, modificar el estado intelectual de nuestro pasado, transformar el modo de ser de nuestra personalidad e impulsar vigorosamente en el sendero del progreso a nuestra patria" (El Escolar Mexicano, 13 de julio de 1889: 6).

Sin embargo, estos maestros, a quienes se les daba tanta responsabilidad y un papel tan importante, eran menospreciados tanto económica como socialmente. Es por esto que ya Ricardo Flores Magón, dentro de su manifiesto de 1906, comentaba que la "noble profesión del magisterio ha sido de las más despreciadas y de las peor pagadas, ya que los maestros, con sus sueldos, solo pueden vivir en condiciones muy inferiores al resto de los profesionistas. De aquí que el porvenir que se ofrece con dicha carrera a los nuevos alumnos, sea solo el de una mal disfrazada miseria" (Constantino, 1971: 60).

Hacia 1903, los maestros de instrucción primaria elemental del Distrito Federal ganaban 40 pesos mensuales. Esta cantidad ni siquiera correspondía al salario de un jornalero en Campeche (46 pesos), Coahuila (46.70), Colima (42.33), Chihuahua (57.66), Morelos (45), Querétaro (48), Tepic (50), Veracruz, (43.39) y Yucatán (95.07) (Galván, 1991: 184 y 185).

En cuanto a los maestros que trabajaban fuera de la ciudad de México, y que ganaban 25 pesos mensuales, esta cantidad era inferior al salario de un jornalero en casi todos los estados, y parecido al más bajo de toda la República, que era el que se ganaba en Aguascalientes (25.14 pesos), Chiapas (25.50), e Hidalgo (25). Solo el de Zacatecas (24.04) era menor en 96 centavos. Lo anterior permite afirmar que, cualquier jornalero en toda la nación obtenía 
un sueldo mayor al de los maestros rurales, quienes trabajaban por una remuneración de entre 15 y 20 pesos mensuales (Galván, ibid.: 185).

Era así como se insistía en la necesidad de mejorar el salario de los maestros. De hecho, personas que habían viajado fuera del país, como Guillermo Prieto, hacían alusión a este problema. Él mencionaba el alto sueldo que recibían los maestros en los Estados Unidos. Sus percepciones fluctuaban entre 600 y 400 pesos al mes, lo cual traía como consecuencia que el profesorado fuera "altamente notable". Comentaba que los salarios altos para el magisterio eran requisito indispensable para que se impartiera una buena enseñanza; terminaba por decir que en cambio, en México, se acostumbraba "dotar maestros sirviendo de norma el salario de los cocheros" (Prieto, 1878: 227).

En cuanto a los ingenieros civiles y los arquitectos, estos ganaban, aproximadamente, 30 pesos por proyecto, si el presupuesto no pasaba de 500. Por planos en terrenos montañosos, con superficie de 20 a 50 hectáreas, 45 pesos, y en plano 35 (Bazant, 1982: 168).

Es difícil hacer un cálculo en relación con los salarios de los maestros, y de otros profesionistas. Sin embargo se ve que, de nuevo, los del magisterio eran más bajos que los de los ingenieros $\mathrm{y}$ arquitectos, pues los 45 pesos que ganaban por un proyecto, los obtenían algunos profesores después de un mes de trabajo diario.

Quien siempre se preocupó por aumentar el salario de los maestros fue el ministro de Instrucción Pública, Justo Sierra; sin embargo, en muchas ocasiones se encontraba con un gran obstáculo: José Ives Limantour, ministro de Hacienda. En varias cartas, Sierra reiteraba a Limantour que el elemento primordial en nuestro país era el maestro. Por eso se necesitaba crearle alicientes. Irónicamente le escribía: "Si sabe usted de alguna fábrica en que hagan maestros de acero o de palo, que no tengan necesidades morales ni físicas, mándeme el catálogo de precios para que encarguemos los diez o veinte millares que la República necesita" (Sierra, 1949: 356 y 357).

Diversas cartas de maestras y maestros, tanto urbanos como rurales, son testigos silenciosos de la triste situación en la que se encontraban. 
Realicemos una lectura de lo cotidiano, de los maestros porfirianos en su tiempo. Entremos en la dimensión de los sueños, pero también de las realidades y escuchemos sus testimonios.

Los imaginarios de los maestros serán diferentes de aquellos de las autoridades. Así, maestras y maestros se dirigían a Porfirio Díaz para exponerle que sus salarios eran muy bajos. Maestras rurales, que por lo general eran viudas, solicitaban una ayuda ya que con lo "poco que ganaban" no podían sostener a su familia. Le comentaban que "agobiadas con los horrores de la miseria" acudían a él para que las auxiliara. Pedían dinero en préstamo y ofrecían pagarlo en abonos, para poner una "tienda de abarrotes", o bien para adquirir una "máquina de escribir o de coser y así obtener algo extra". Afirmaban que, tanto la renta de las casas como el precio de los alimentos, habían aumentado mucho y lo poco que tenían ahorrado ya no les alcanzaba para salir adelante (C. P. D., L. 33 , C. 9 , D. 3454 , C. 15 , D. 5849 , y C. 18 , D. 7054 ).

La necesidad de los maestros de retirarse y descansar, los llevaba a solicitar su jubilación. En primer lugar, le escribían a Díaz y le explicaban su situación. Por lo general, se trataba de maestras y maestros que habían trabajado durante 35 y 40 años; otros más, que tan solo habían prestado sus servicios durante 20 años, pedían media jubilación.

En algunas ocasiones solicitaban que se les diera la jubilación, pero "conservando" su empleo. De hecho, las pensiones de jubilación eran muy bajas; en ocasiones no correspondían al sueldo íntegro del maestro, lo que representaba solamente una percepción de 15 o 20 pesos mensuales. Con ese dinero, indicaban, no les alcanzaba ni para llevarse un "pedazo de pan a la boca". Por ello le pedían a Díaz que, después de tantos años de trabajo, no los abandonara "a la miseria y a la muerte". A este tipo de peticiones, la respuesta que se les daba era negativa. Se argumentaba que al decretarse la jubilación no se podría desempeñar ningún empleo, ya que esta se fundamentaba en la "incapacidad de los agraciados".

En otras ocasiones, maestros de provincia le pedían a Díaz los recomendara con los gobernadores para obtener su jubilación, ya que habían trabajado por más de 30 años "sin interrupción" y añadían que además habían contraído enfermedades debido a ese "trabajo mental" que desempeńaban. Por lo general en todas estas 
peticiones se hacía alusión a que no gozaban de buena salud ya que habían dejado parte de su vida en las aulas, y ahora no podrían "consagrarse como en otras épocas" a su profesión, y además se les había indicado que no se les podía dar la jubilación que deseaban porque "los fondos del erario no lo permitían" y que por lo tanto se dirigieran al "Gobierno General". Una vez que le escribían a Díaz, de nuevo se les daba una respuesta negativa, en el sentido de que el asunto de la jubilación solo correspondía al gobierno del estado donde habían prestado sus servicios. Por ello, en ocasiones, los propios gobernadores intercedían ante Díaz para que se le concediera la jubilación a un determinado maestro que había trabajado durante más de 50 años y se encontraba en malas condiciones económicas.

De hecho, los propios maestros sabían que, si no habían trabajado todo el tiempo en la ciudad de México, era muy dificil que tuvieran derecho a la jubilación. Una maestra que había trabajado durante 35 años, primero como directora en escuelas de Puebla y del estado de México, y luego como ayudante en el Distrito Federal, le comentaba a Díaz que no tenía la seguridad de que a ella le tocara la "gracia de la jubilación", pero que confiaba en que él le "concedería ese favor".

Otro era el caso de una maestra que había trabajado durante 32 años y pedía su jubilación. Sin embargo esta le había sido negada ya que de esos años, 19 los había pasado en las escuelas de Oaxaca, y solo 13 en las del Distrito Federal como ayudante, por lo tanto el jefe de la Sección de Instrucción Primaria y Normal, Gregorio Torres Quintero, le contestaba que "no tenía el tiempo que marcaba la ley" para que se le concediera la jubilación (C. P. D., L. 33, C. 6, D. 2338 y 39 ; C. 8 , D. 3011,3101 y 02 ; C. 15 , D. 5643 ).

La situación de diversos maestros era tan difícil que a veces, aun cuando lograban conseguir un empleo, no podían presentarse a trabajar por la "falta absoluta de ropa"; además - decían- la gente "es demasiado exigente juzgando por apariencias". Uno de ellos hacía alusión a que su "traje raído" era una "rémora para trabajar y ser aceptado". Comentaban que estaban muy pobres para poder adquirir ropa y por lo tanto, con urgencia se la pedían a Díaz, ya que temían que los reemplazarían por no presentarse a tiempo en sus escuelas (C. P. D. L. 33, C. 3, D. 1116 y 118, C. 7, D. 2461 y 2465. 
Al lado de las peticiones de ropa, encontramos las de material bibliográfico. Maestros rurales pedían libros para "superarse" en su carrera. Comentaban que, por no ganar lo suficiente para poder adquirir libros, solicitaban que Díaz les proporcionara los que "a su juicio" considerara convenientes. Otros maestros que, por trabajar lejos de las capitales de los estados, tampoco podían obtener libros, le enviaban al presidente las listas de los que necesitaban.

De hecho, al terminar la Revolución, algunos de los maestros rurales que se preocupaban por estar mejor preparados participaron activamente al lado de José Vasconcelos. A manera de ejemplo, podemos hablar del maestro Enrique Corona, quien desde 1909 le escribía a Díaz pidiéndole determinada bibliografía, y más tarde, en 1923, lo encontramos participando con Vasconcelos, ya que fue él quien redactó el proyecto por el cual se fundaron las Casas del Pueblo (A. G. N. Instrucción Pública y Bellas Artes, caja 196, exp.11, folder 6 y C. P. D., L. 34, C. 2, D. 1680; C. 3, D. 1454; C. 19, D. 9129).

Estos ejemplos nos dejan ver cómo, por un lado, estará el discurso sobre el maestro imaginado durante el porfiriato y, por el otro, su realidad, su vida cotidiana. El descontento con su profesión, con sus bajos salarios y mala preparación, hará que algunos maestros decidan participar en el movimiento revolucionario de 1910.

El porfiriato fue incapaz de asimilar al maestro, principalmente al rural y este, inconforme con la crisis económica y social por la que atravesaba, se unió a los revolucionarios. De aquí que ahora nos asomaremos por la ventana del tiempo para mirar cómo algunos maestros se convirtieron en revolucionarios. Se trata, principalmente, de profesores de tercera clase, o sea aquellos que no habían terminado sus estudios, cuya falta de preparación académica y la falta de un título, los habían empujado a buscar trabajo en el campo.

Estos maestros rurales no poseían bien alguno. Muchos de ellos dormían en las mismas escuelas y escribían a Díaz para hacerle diversas peticiones. Sin embargo, frente a la comunidad rural, por lo general representaban algo más, un modelo a seguir. Luis González y González comenta que, cuando el saber leer, escribir y contar "se puso de moda", los jefes de familia en las rancherías solían juntarse para "pagar un maestro". En ese momento, los pro- 
fesores eran las personas más instruidas en los pueblos ya que ellos poseían los conocimientos de la época (González y González, 1984: 30).

Muchas eran sus necesidades, pero quizás las del pueblo en donde prestaban sus servicios eran mayores. Ellos estaban en contacto diario con las injusticias que padecían los jornaleros en el campo. De aquí que algunos de ellos se rebelaron de diversas maneras. Sus frustaciones los llevaron a rechazar el régimen que, durante muchos años, habían aceptado. Paradójicamente, el control del magisterio por medio de un bajo salario, llevó a algunos maestros a la rebelión.

Entre las filas de Carranza, en el norte, encontramos algunos maestros como Cándido Guajardo, profesor en Progreso, Coahuila, quien se le unió como soldado de su ejército; también maestro coahuilense, Ignacio Cortinas, murió en combate en 1916, peleando al lado de los carrancistas; Nemesio Báez Ocampo, maestro en Colima, quien se le unió al estallar la revolución y José Rivera, maestro en Tula, Hidalgo, quien murió en combate en 1914, entre otros más (Galván, 1992: 20-21).

Por otro lado, Álvaro Obregón también contó con la ayuda de varios maestros como Gustavo Villatoro, chiapaneco que primero se unió a Carranza en 1914 como soldado raso, y en 1915 pasó a ser oficial del estado Mayor de Obregón; José Ángel Ceniceros, oriundo de Durango quien, siendo estudiante, se unió al ejército del noroeste. Los maestros sinaloenses Manuel Páez e Ignacio Noris, realizaron sus estudios en la Normal del estado y al estallar la revolución se unieron al ejército obregonista, por tan solo mencionar algunos (Galván, ibid.: 21).

Otros maestros como Esteban Baca Calderón, Moisés Sáenz y Abraham Castellanos, también tuvieron importantes participaciones en la Revolución. El primero, oriundo de Nayarit, llevó a cabo sus actividades revolucionarias en Cananea, Sonora. Fue general constitucionalista y en 1917 candidato a la gubernatura de su estado natal (Cockroft, 1967: 569).

Moisés Sáenz, oriundo de Nuevo León, donde ejercía como maestro de primaria, se unió al constitucionalismo en 1914. En cuanto a Abraham Castellanos encontramos que nació en Nochixtlán, Oaxaca, y estudió en Veracruz. En 1910 fue nombrado 
Inspector de Educación Primaria en Colima. Se levantó en contra de Huerta, fue encarcelado y murió en 1918 (Naranjo, 1935: 192 y Quiroz, 1962: 41).

En el sur, en las filas zapatistas, encontramos al maestro Francisco Figueroa, importante líder revolucionario en Guerrero. Por su parte, Otilio Montańo, profesor en Morelos, se unió a Zapata con quien colaboró en la redacción del "Plan de Ayala" en 1911. Dentro de este grupo podemos mencionar a Antonio Acevedo, estudiante de la Normal de Maestros del Distrito Federal, quien en 1911 se unió a los zapatistas (Cockroft, 1967: 567 y Constantino, 1970: 98).

Destaca también la figura de Librado Rivera, quien estudió en la Escuela Normal de San Luis Potosí, donde dirigió la escuela "El Montecillo”. En 1901 participó en el Primer Congreso Liberal, donde conoció a Ricardo Flores Magón. De 1905 a 1908 participó en revueltas y huelgas y llegó a ser editor de Regeneración, al mismo tiempo que mano derecha de Ricardo Flores Magón en el exilio (Cockroft, 1967: 572).

Importante también fue la participación de las maestras, quienes efectuaron tareas de correo, enlace, enfermería, etc. Entre muchas otras podemos mencionar a Francisca, Julia y Carolina Blackaller, quienes junto con Esther Colunga, se unieron a Carranza como enfermeras. Se trasladaron a Eagle Pass, Texas, donde atendían a los heridos del ejército constitucionalista (Entrevista con la maestra Francisca Blackaller, 1979).

En 1912, Mariana Gómez Gutiérrez era maestra de una escuela primaria rural en Ojinaga, Chihuahua. Estableció contacto con los magonistas y ayudó a distribuir Regeneración. Primero se unió a Madero y después a Villa, con quien luchó en contra de los orozquistas en 1913 (Archivo Turner, Blas Lara...).

Otra maestra, Guadalupe Romero viuda de González, se encontraba trabajando en una escuela primaria rural en Morelos. Se unió a los zapatistas. Poco a poco fue colaborando con ellos, mediante las tareas de enlace y correo que realizaba (Mendieta, 1961: 109).

En Puebla contamos con la participación de varias maestras que difundieron las ideas revolucionarias en sus escuelas, atendieron hospitales de campaña, consiguieron auxilios para la población civil, ejecutaron labores de enlace y correo, y llegaron a ser comba- 
tientes. Fueron, entre muchas otras, Guadalupe Narváez, Paulina Miravar, Herlinda, Enriqueta, Natalia y Hortensia Pinto, Aurelia Báez y Carlota Ramírez (Mendieta, ibid.: 55-58).

En Veracruz, Ma. Josefa Álvarez, profesora rural, fue la encargada de difundir las ideas revolucionarias entre sus colegas. Más tarde colaboró como enfermera en el ejército de Carranza (Sáenz, 1960: 39). Entre las maestras de Yucatán podemos mencionar a Rosa Torres González, quien colaboró activamente al lado de los revolucionarios yucatecos (Mendieta, 1961: 111).

Finalmente, podemos hablar de Eulalia Guzmán, oriunda de Zacatecas, quien estudió en la Normal de Maestras del D. F. A raíz de la muerte de Madero fundó, junto con María Arias Bernal, subdirectora de la escuela "La Corregidora de Querétaro" y otras maestras, el "Club Lealtad”. Este club tenía como fin concertar entrevistas y formar nuevos enlaces en pro de la Revolución. También visitaban a los presos políticos que habían sido encarcelados por Victoriano Huerta. Debido a su participación en la revolución fue cesada (Constantino, 1970: 100).

Estas maestras y maestros representan tan solo algunos de los que participaron en el movimiento revolucionario. Nombrarlos a todos equivaldría a una lista interminable. Sin embargo, estos ejemplos son una importante muestra de que el "imaginario" del maestro construido durante el porfiriato no funcionó. El maestro no estaba conforme con su situación y por ello se rebeló. El maestro no podía vivir solamente de "bellos discursos", muchas eran sus necesidades y, de diversas formas, las expresó a través de su actitud contestataria ante el régimen.

Una de estas formas contestatarias de expresión, además de su participación en el movimiento revolucionario, fue también por medio de las huelgas. El antecedente directo de estas huelgas fue el hecho de que, el 15 de abril de 1917, Carranza declarara que consideraba al magisterio "como el más notable apostolado y la eficacia del ejemplo en la formación del carácter..." (González y González, 1966: 172). Sin embargo, en ese mismo año, suprimía la Secretaría de Instrucción Pública y Bellas Artes, y se creaba el Departamento Universitario y de Bellas Artes. Esta medida trajo como consecuencia el que la educación quedara en manos de los ayuntamientos. 
Esta medida en nada ayudó al mejoramiento de la instrucción pública, y menos a la de los maestros. Para 1919, había ya dos mil maestros de la capital declarados en huelga, debido a que no se les había pagado durante meses. Los obreros apoyaron la huelga y amenazaron con dejar de trabajar si no se resolvía el problema de los profesores. La Facultad de Leyes y la Escuela Nacional Preparatoria apoyaron la huelga y suspendieron sus labores (Llinás, 1978: 97).

Los estudiantes normalistas también apoyaron a los maestros, e iniciaron un paro de actividades. Sin embargo, todos estos movimientos de nada sirvieron. Alberto Pani nos comenta que, después de que los ayuntamientos decidieron que no podían pagarles sus sueldos a los maestros de las escuelas primarias superiores, se les remitió a la Secretaría de Hacienda, esta "los devolvió a su turno a los ayuntamientos, que a su vez los rechazó de nuevo". Los maestros "casi enloquecidos" buscaron el apoyo de los maestros de escuelas elementales, quienes se les adhirieron. Todos decidieron declararse en huelga; "se les hizo cesar, entonces, en masa" (Pani, 1918: 114).

Con objeto de defenderse ante tantas arbitrariedades surgieron las primeras asociaciones de maestros, como la que encabezó José de la Luz Mena en 1917, llamada "Liga de Maestros Racionalistas". En 1919 se formó la "Liga de Profesores de la Ciudad de México", que proponía que la educación dependiera directamente del Poder Ejecutivo Federal (Diario de los Debates de Senadores, 14 de mayo de 1919: 7).

El fracaso de los ayuntamientos fue tan grande que, a la caída de Carranza, Adolfo de la Huerta dispuso que el Departamento Universitario se constituyera en un organismo destinado a la orientación y vigilancia de la educación en todo el país y que tuviera a su cargo las escuelas del Distrito Federal (Entrevista con el maestro Juan Robles, 1978).

En septiembre de 1920, el Presidente anunciaba ante el Congreso que se había terminado ya el proyecto para llevar a cabo la federalización de la enseñanza y que se había progresado mucho en la campaña contra el analfabetismo, que había quedado a cargo del Lic. José Vasconcelos, como rector de la Universidad.

Todo esto vaticinaba tiempos mejores para las maestras y maestros mexicanos, quienes habían puesto sus esperanzas en el movimiento revolucionario. 


\section{EL ESCENARIO POSTREVOLUCIONARIO (1920-1940)}

A nadie escapa la labor realizada por José Vasconcelos al frente de la nueva Secretaría de Educación Publica en 1921. Muchos de los planteamientos expuestos en esa época perduraron durante toda la década de los ańos veinte; esto es muy importante para comprender lo que sucedió más tarde, en los años treinta. De hecho, es Vasconcelos quien imagina tanto una determinada política educativa, como un determinado maestro que sirviera a los intereses de dicha política.

Este secretario se preocupó porque en las escuelas rurales no solo se enseñara a leer, contar y escribir, sino que se llevara a cabo un programa integral que penetrara en los poblados. Por medio de dicho programa se quería una transformación radical consistente en "mejorar hogares, mejorar métodos de trabajo y mejorar la salud y el ambiente espiritual". El fin era crear en todas las aldeas "sentimientos e intereses comunes para poder formar una verdadera nacionalidad” (Murillo, 1949: 1).

En febrero de 1925 se expidió un plan de trabajo para las escuelas rurales que tenía como fin guiar a los maestros en su labor educativa. Se quería que la escuela reflejara la vida diaria, que no hubiera lecciones orales, ni horarios rígidos, ni reglamentos estrictos. Se pensaba que la base de la enseñanza eran las relaciones del niño y del hombre con la tierra. En las escuelas rurales no habría castigos ni premios, sino que se dejaría al niño en libertad para que fuera espontáneo. Se formarían comités de deportes, juegos y talleres, integrados por los propios alumnos para crear dentro de la escuela una verdadera democracia (Galván, 1985: 78).

Para poder desarrollar el plan de trabajo que acabo de describir, surgió la necesidad de imaginar maestros que tuvieran determinadas características. Se quería que conocieran el medio en el que iban a trabajar y que se sintieran ligados con el campesino. También se les haría comprender que deberían acentuar su temperamento y sus cualidades de líderes sociales (ibid.).

Con objeto de llevar a cabo este plan, el Ministro de Educación imaginó a sus "misioneros", quienes serían los encargados de pre- 
parar a los maestros rurales. El propio Vasconcelos decía: “A falta de un maestro completo como el fraile que sabía cultivar un campo, aserrar y ensamblar una mesa, nosotros empezamos a mandar grupos de maestros: uno de artesanías, otro que enseñara a labrar la tierra y a forjar el hierro, otro que fuera un artista y pudiera inspirar en la población el gusto de la belleza, otro más para que incitara a la acción social y a la colaboración patriótica y otro, finalmente, para las primeras letras y las matemáticas. Y nació así el misionero de tipo moderno" (Vasconcelos, 1938: 141).

Se empezó por seleccionar cinco zonas y se estudiaron sus necesidades. Después se envió a cada una de estas regiones una Misión compuesta por un ingeniero agrónomo, un médico higienista, una enfermera partera, un maestro de industrias locales, una trabajadora social, un carpintero y un albañil (Galván, 1982: 82).

Varios eran los objetivos que se propusieron con la creación de estas misiones. Entre los más importantes tenemos: preparar a los jóvenes para el magisterio, despertar en los campesinos sentimientos de admiración por los héroes, enseñarles nuestro "pasado glorioso", explicarles sus deberes cívicos, impartir pláticas de higiene, combatir los vicios dominantes del pueblo y mejorar las industrias existentes. Es necesario entender el término "industria” como artesanías y oficios, más que como industrias pesadas, para poder comprender los objetivos de los misioneros. Así, se proponían "promover el progreso económico de las comunidades, gracias a la divulgación de la enseñanza agrícola y de las pequeñas industrias" (A. H. SEP, 1925: 12-9-1-395).

Vasconcelos se inspiró en la labor de los frailes del siglo XVI para crear a sus "maestros misioneros". El misionero moderno era un maestro normalista que guiaba a un grupo de educadores y convivía con los campesinos, ayudándolos a levantar la escuela con los recursos locales y preparando a los jóvenes para que quedaran al mando de la enseñanza. En su afán por encontrar maestros rurales, Vasconcelos inició la búsqueda con 77 misioneros, quienes eran profesores voluntarios (Entrevista con la maestra Alicia Cortinas, 1979).

En cuanto al método utilizado, empezaban por elegir una pequeña comunidad donde se concentraban los maestros. Al llegar los misioneros, se abría un Instituto de Perfeccionamiento y de 
Acción Social, cuyas labores duraban 21 días, y después pasaban a otra región para hacer lo mismo. El trabajo se realizaba tanto con los maestros, como con los campesinos. Posteriormente extendió su acción a toda la comunidad. Se construyeron locales para escuelas, teatros al aire libre, jardines públicos, salones de lectura y casas modelo para el campesino. En cuanto a los maestros, se les orientaba en el magisterio rural y se les organizaba en ligas con sentido sindicalista (Entrevista con el maestro Alfonso Ramírez, 1977).

Los primeros misioneros debían ser administradores, supervisores, maestros y filósofos. Tannenbaum comentaba que "El misionero pronto descubrió que era el único representante de la civilización moderna en la comunidad rural. Si había de salvarse el abismo entre lo rural y lo urbano, él era quién tenía que tender el puente. Debía ser todas las cosas para todos los hombres" (Tannenbaum, 1949: 91).

Los misioneros dejaron en los maestros nuevas ideas e inquietudes, tales como las nuevas técnicas pedagógicas, las formas de integrarse a la comunidad y relacionarse entre ellos mismos. Así, por ejemplo, los maestros que asistieron a la Misión Cultural en Tepehuanes, Durango, decían que “...la misión fue para nosotros como ráfaga de luz misteriosa que inquietó nuestro espíritu por la serie de problemas que propuso y cuya respuesta es de carácter ineludible" (SEP, 1928: 382-83).

En el Archivo Histórico de la SEP encontré varios testimonios de maestros que asistieron a los cursos que impartían las Misiones Culturales. Así, Juan N. Resendiz decía que “...lo único que siento es que lo que he aprendido en el Instituto, lo debía de haber aprendido antes, ya que por medio de estas orientaciones se han aumentado mis recursos para el desempeño de la augusta carrera del magisterio" (A. H. SEP., 1927: 12-9-1-398: 4 y 5).

Por su parte, el maestro A. Benítez comentaba que "... lo que he aprendido en el Instituto de Atlacomulco hace que ahora asista a mi escuelita lleno de anhelos a cumplir con mi misión". En San José del Cabo, una profesora opinaba que "las Misiones Culturales se establecieron como lógica consecuencia de los propósitos de la Revolución mexicana, logrando así el mejoramiento social de las clases más humildes de nuestro pueblo" (A. H. SEP, ibid.: 6 y 7 ). 
Los maestros de la Municipalidad de Comundú decían que en 21 días habían aprendido los trabajos de jardinería, agricultura, deporte, técnica industrial, biblioteca, sociología práctica, enfermería, trabajos manuales, corte de ropa, gimnasia rítmica, juegos de estrado y fiestas culturales. De este modo, las Misiones Culturales no se limitaban a alfabetizar al pueblo, sino que tenían todo un programa de diferentes actividades, muchas de ellas encaminadas a mejorar el nivel de vida de las comunidades (A. $\mathrm{H}$. SEP, ibid.: 10).

Dentro de las misiones también hubo fracasos, y así, encontré que la Misión de Ocotlán no tuvo éxito debido al "fanatismo de la región, a la ausencia de tranquilidad social por la frecuente aparición de bandoleros, a la falta de cooperación moral de la Dirección de Educación Federal en el Estado y a la desorganización en que se encontraban las escuelas" (Entrevista con el maestro Pedro Martínez, en 1978).

Por su parte, el profesor Matías López, de Pachuca, Hidalgo, decía: "lamento sobremanera que las causas especiales en que trabajó la Misión, no hubieran sido favorables a tan noble causa y que ello trajera como consecuencia muy relativos resultados favorables a los maestros que con tantos sacrificios asistieron, máxime cuando la propia Misión dejó tan pocos gratos recuerdos en otros propios lugares del estado" (A. H. SEP, 1927, 12-9-1-398: 12).

En este mismo archivo existen también testimonios de maestros misioneros. Así el maestro agrónomo, Marcelino, apuntaba: “...se trataba de ir a enseñar agricultura, tanto a los maestros, como a los vecinos del lugar. De ir a decirles a los maestros cómo deberían emplear esa enseñanza en sus trabajos que están desarrollando en la escuela rural; y a los campesinos no solo resolverles las consultas y dificultades desde un punto de vista meramente científico o práctico, sino también advertirles, previo estudio, sus problemas económicos" (A. H. SEP, ibid.: 18).

Por otro lado, el ingeniero que participó en la Misión Cultural de Atlacomulco afirmaba que era necesario “...organizar y orientar la enseñanza agrícola en las escuelas rurales en bien de las nuevas generaciones, en bien de la escuela y de la comunidad en la que trataba de estrechar fuertes lazos de cooperación y trabajo para asegurar en un futuro no lejano, la libertad económica de 
nuestro pueblo como base fundamental de una efectiva libertad política y social" (A. H. SEP, ibid.: 22).

La riqueza de estos documentos nos deja ver que existía un gran empeño por parte no solo de las autoridades, sino también de los maestros misioneros, por llegar, tanto a los maestros rurales, como a las comunidades donde se desempeńaban, con objeto de cumplir con aquello que Vasconcelos apuntaba ya desde 1922 cuando imaginaba a sus maestros. El ministro de Educación, en uno de sus discursos en 1922, hablaba del maestro como aquel que "dominaría la materia, tendría habilidad disciplinaria, sería puntual, desarrollaría bien el trabajo administrativo, tendría interés en las actividades sociales, pondría empeño en su perfeccionamiento profesional, y tendría buena conducta dentro y fuera de la escuela" (A. H. SEP, Ref. 58, exp.1, año 1922-1924).

A lo anterior, hacia 1925 , se agregaba que el maestro debería de organizar el huerto escolar de acuerdo con los cultivos de la región, procurando siempre mejorarlos e introduciendo otros nuevos. Ellos serían también los encargados de decidir sobre las pequeńas industrias que se deberían de introducir en la escuela y organizar un campo de deportes para el desarrollo del programa de educación física, además de arreglar el local de la escuela con el fin de que este fuera un "medio poderoso de cultura social" (A. H. SEP, Ref. 64, exp.16, año de 1925).

Por otro lado, se consideraba que una buena maestra sería aquella que tuviera las siguientes cualidades: "sumisa, obediente, amante de la educación moderna, y que fuera cariñosa con sus alumnas a quienes debería ayudar hasta pecuniariamente". Se le pedía también que procurara enriquecer sus conocimientos estudiando y consultando "buenos autores, con el fin de que en el reconocimiento final tuviera resultados muy satisfactorios" (A. H. SEP, Ref. 64, exp.18, año de 1925).

Además de las obligaciones con las que tenía que cumplir el maestro al interior del aula, también se le daban una serie de responsabilidades que tenía que cumplir con la comunidad. Constantemente se le recordaba que es "necesario que cada maestro federal se convierta en factor de mejoramiento y progreso en el pueblo en que presta sus servicios". A lo anterior se aunaba el que sábados y domingos ningún maestro ni maestra podía separarse 
del lugar en donde estaba su escuela con objeto de que "intensificara su labor social” (Entrevista Mtra. Adela Palacios, 1978).

Dentro de este trabajo que tenía que desarrollar el maestro con la comunidad, encontramos que también tenía que cumplir con la "Hora de la lectura", la cual había sido "creada por acuerdo del C. secretario de Educación Pública, Lic. Ezequiel Padilla”. Durante esta hora tenía que leerles a los campesinos el periódico El Sembrador. Esta publicación era gratuita y se repartía en toda la República (B. L. A. C., SEP, El Sembrador, núm. 8, 1929).

Ahora bien, parte importante de la campaña de Vasconcelos se basaba en la educación para el campo, idea que continuó posteriormente. Es así cómo hacia 1926 se habla de que "a pesar de las limitaciones de presupuesto, se ha aprobado la creación de mil nuevas escuelas rurales, y se ha ampliado a diez el número de $\mathrm{Mi}$ siones Culturales". Lo anterior se debía a que, decían, "existen numerosísimos poblados que por su alejamiento, no han conseguido hasta ahora los beneficios de una escuela rural". Dichas escuelas se instalarían en lugares donde no había ningún establecimiento educativo (B. L. A. C., SEP, El sistema de escuelas rurales, 1927).

El presidente Emilio Portes Gil consideraba al maestro, como "el primer factor de la escuela", de aquí la necesidad de "estimularlo y garantizarlo como un trabajador intelectual que rinde enormes servicios a la República”. Es por esto que se habían formulado proyectos de leyes de jubilación, de estabilidad y escalafón magisteriales, al igual que se había fomentado la construcción de la Casa del Maestro (B. L. A. C., SEP, El Sembrador, núm. 1, 1929). Todo esto se debía a que, cuando se imaginó al maestro rural, nunca se pensó que se trataba de una persona normal, quien tendría muchas necesidades y que no podría alimentarse tan solo del discurso. No hay que olvidar que, hasta 1929, el magisterio no contaba con ninguna prestación social.

En otro discurso, este mismo presidente se refería a que la "educación de las clases trabajadoras de México es el único camino seguro de su positiva redención”. De aquí que su esfuerzo se concentrara en extender la enseńanza rural en toda la República (B. L. A. C., SEP, El Sembrador, núm. 2, 1929).

Sin embargo este deseo, que en no pocas ocasiones será parte del imaginario de la educación pública, se encontraba con el proble- 
ma de la falta de recursos económicos para lograrlo. De aquí que se insistiera en la necesidad de que las comunidades campesinas sostuvieran las escuelas rurales por medio del sistema denominado de "Circuitos rurales". Dicho sistema consistía en que un maestro central, pagado por la Federación, organizaba, vigilaba y dirigía, en continuas visitas a escuelas circundantes, sostenidas por las propias comunidades (B. L. A. C., SEP, ibid.).

$\mathrm{Al}$ problema anterior se aunaba el de la falta de maestros preparados. Se decía que la "urgencia con que los gobiernos revolucionarios han considerado la enseñanza del pueblo, ha obligado a la SEP a improvisar maestros para las escuelas rurales". De aquí la necesidad de "no abandonar a los maestros rurales en su impreparación”. Es por esto que se habían organizado las Misiones Culturales que tenían, entre otras, la finalidad de impartir cursos breves a los maestros, como señalé anteriormente. De algún modo, los diversos secretarios de Educación Pública entre 1920 y 1940 , imaginarán a un maestro que deberá tener ciertas características. Sin embargo, en la realidad, se tratará tan solo de un imaginario más dentro del discurso de la política educativa mexicana.

$\mathrm{Al}$ iniciarse los años treinta se reforzó esta política educativa hacia el campo. Narciso Bassols, ministro de Educación en 1932, imaginaba que la escuela rural era la "dádiva generosa que la Revolución ha dado a los campesinos” (B. L. A. C., SEP, El Maestro Rural, núm. 10, 30 julio de 1932).

Durante la década de los treinta, parte importante de este discurso se centraba también en el maestro. En este imaginario que será el maestro rural. Se decía que era él quien pondría la "simiente en el alma para que surja prepotente la virtud y broten los sentimientos del deber, de la justicia y del derecho". Se afirmaba que el maestro rural era aquel que "trueca su vida y su felicidad por la grandeza de la patria, sin otra recompensa que la satisfacción del deber cumplido" (B. L. A. C., SEP, ibid.).

Se insistía en que el maestro rural debería de ser un "buen agricultor", para ello se proponía vincular las escuelas Normales a las escuelas de Agricultura Práctica. Se recordaba que, debido a la importancia que tenía el maestro rural, su preparación debería ser "constante" (B. L. A. C., SEP, El Maes tro Rural, núm. 1, $1^{\circ}$ de enero de 1933). 
Al finalizar 1934, encontramos un cambio muy importante dentro de la política educativa del país. Así, el 19 de octubre, el Senado de la República aprobaba el Proyecto de Reforma al Artículo $3^{\circ}$ de la Constitución Nacional, estableciendo la enseñanza socialista en lugar de la enseñanza laica (36 votos a favor y 13 en contra). El discurso, al igual que sus imaginarios, va a cambiar, debido a que una nueva política educativa lo anima.

Se habla de que la educación socialista persigue "identificar a los alumnos con las aspiraciones del proletariado, fortalecer los vínculos de solidaridad y crear para México, de esta manera, la posibilidad de integrarse revolucionariamente dentro de una firme unidad económica y cultural". Por medio de la escuela socialista se llegaría al "terreno de bienestar económico y moral que ambicionamos para México". Se imaginaba así que los maestros rurales serían los "soldados de que se vale la Revolución para realizar una campaña desfanatizadora entre las masas campesinas del país" (B. L. A. C., SEP, El Maestro Rural, núms. 10 y 12, nov. y dic. de 1934).

Al subir Lázaro Cárdenas a la presidencia, su discurso siguió también por el camino de la enseñanza socialista. Se trataba de un discurso triunfalista donde se imaginaba dicha educación como la panacea que acabaría con todos nuestros males.

Se hablaba de que la "implantación de la escuela socialista significaba un paso más hacia la redención material y espiritual de las clases asalariadas, dentro de un orden de efectiva justicia social”. Para lograr dicho propósito se mencionaba la necesidad de "liquidar el analfabetismo de las masas y destruir los privilegios de la cultura poniendo la escuela al alcance de las clases laborantes” (B. L. A. C., SEP, El Maestro Rural, núm. 4, febrero de 1935).

Se imaginaba, así, que la educación socialista se dirigiría hacia "las masas campesinas y obreras". De nuevo, en este discurso, se enfatizaba la necesidad de difundir y adentrar en los espíritus dicha ideología, con objeto de que "la clase explotada se organizara en sindicatos y cooperativas, que le permitieran defender sus derechos" (B. L. A. C., SEP, ibid.). Todos estos discursos pertenecían al imaginario de la educación socialista que se estaba construyendo.

Por otro lado, se hablaba de que los maestros deberían de encauzar la "campańa desfanatizadora”. De aquíla necesidad urgente de 
formar una "conciencia revolucionaria" en el magisterio, y que este, poco a poco, fuera adquiriendo para su estudio, obras de "izquierda en consonancia con las aspiraciones del momento histórico en que se vive" (A. H. SEP, Ref. 295, exp 8, año1936).

En otros discursos se puede encontrar otra cara de este imaginario. En algunos se referían al maestro como "el arquitecto esforzado de la reforma educacional”, como aquel que esparcía la "simiente en los surcos de las mentes, fertilizándolas para producir una nueva sociedad", como aquel que iba "moldeando a las futuras generaciones". A lo anterior se aunaba la idea de que "los maestros rurales tienen la satisfacción de luchar por la elevación de nuestro nivel cultural. Poco a poco, con su labor desanalfabetizadora, van desterrando los mitos que no permiten que nuestro pueblo crezca y madure" (B. L. A. C., SEP, El Maestro Rural, núm. $11,1^{\circ}$. de junio de 1935).

Esta pequeńa muestra de algunos discursos, muestra lo que se quería que fuera la escuela y el maestro rural, imaginarios que las autoridades fueron creando a través de dos décadas de discursos. No obstante, queda todavía otro nivel por resolver, el de su vida cotidiana, el de su realidad. Se le imaginaba como una persona en quien recaían muchas obligaciones, sin embargo, poco sabemos sobre sus derechos.

El tiempo nos permite internarnos en otra dimensión, aquella del maestro rural imaginado e inventado por las autoridades educativas en las décadas entre 1920 y 1940, la cual estaba muy alejada de su realidad. De aquí que se pueda decir que una cosa será el discurso y otra su vida cotidiana. Para afirmar lo anterior me baso tanto en testimonios de las propias autoridades, como en aquellos de los maestros.

Hacia 1929, el jefe del Departamento de Escuelas Rurales, Profesor Rafael Ramírez, decía que había más de 5000 maestros rurales que estaban haciendo una "obra maravillosa”, ya que en términos generales no habían recibido una preparación especial para maestros. Se habían elegido de entre las personas que, sabiendo leer y escribir, daban muestras de alto espíritu de servicio. En el trabajo mismo se habían ido adiestrando en "el arte de enseñar a lo niños y adultos y en la ciencia de mejorar las condiciones de vida de la comunidad en que trabajan”. Estos educadores debían hacer un 
triple trabajo: enseñar a los niños, enseñar a los adultos y mejorar la comunidad. Con objeto de que todo esto se lograra, los habían arraigado en las comunidades, obligándolos a vivir en ellas (B. L. A. C., SEP, ElSembrador, núm. 4, 5 de junio de 1929).

Posteriormente, el ministro de Educación en 1932, Narciso Bassols, reconocía que la labor educativa no se podía realizar si no se atendía el problema de los maestros, tanto en su preparación como en sus bajos salarios. De aquí que dijera que la escuela rural necesitaba afianzarse por medio de la "elevación de los maestros, mediante su preparación mejor y más completa, lo que solo será posible cuando desaparezcan los sueldos de 27 pesos al mes que ganan hoy los maestros rurales. Las escuelas rurales trabajan en un ambiente de heroico esfuerzo hecho por el maestro rural para vencer la escasez de elementos, de materiales escolares, de equipos". Finalmente, hablaba del "maestro heroico que vive y trabaja por el santo milagro de la nobleza de la causa, compartiendo con el campesino sus miserias y dolores, sus afanes y desvelos" (B. L. A. C., SEP, El Maestro Rural, núm. 10, 30 de julio de 1932).

Una conquista importante de los maestros rurales en 1933 fue el aumento de sus sueldos de 1.00 y 1.50 pesos, a 2.00 al día. Se decía que los anteriores salarios "no garantizaban un trabajo eficaz". Sin embargo, a pesar de este pequeño aumento, su situación no había mejorado mucho, y esta era descrita por los mismos maestros (B. L. A. C., SEP, El Maestro Rural, núm. 8, 15 de septiembre de 1933).

Entre los problemas a los que tenían que enfrentarse los maestros en su vida diaria se encontraba el hecho de la baja asistencia escolar. Los padres de familia, tanto en la década de los veinte como en la de los treinta, "preferían que sus hijos trabajaran con ellos en el campo o en las artesanías, en lugar de enviarlos a la escuela" (Entrevista con la maestra Chávez, 1978).

Sobre la inasistencia escolar, las autoridades reconocían dos causas principales: a) "la época de lluvias que aprovechaban los pueblos para hacer su siembra anual" y b) "la cuestión religiosa". Comentaban que era "imposible destruir la primera causa, ya que los pueblos, en la mayor parte del territorio nacional, eran muy pobres, y necesitaban el trabajo de los niños para ayudarse en sus faenas en el campo" (A. H. SEP, Ref. 64, exp. 16, años 1925-26). 
En ocasiones, las escuelas quedaban sin población escolar, no solo en la época de levantar las cosechas, sino también durante algunas fiestas religiosas importantes para las comunidades, como las del 2 de febrero, día de la Calendaria, los "días santos de la Semana Mayor", el 3 de mayo, en que se festejaba la Santa Cruz, o bien el 24 de junio, día de San Juan, entre otras que estaban relacionadas con el santoral específico de cada región. Estas festividades duraban, por lo menos, una semana, tiempo en el cual los niños no asistían a la escuela (entrevista maestro Pedro Martínez, 1978).

Se enfrentaban así dos dinámicas: la de la escuela, y la de la comunidad, ya que esta no modificaba su vida cotidiana en función de la escuela. De hecho, se trataba de dos sistemas festivos, por un lado el establecido, el popular o religioso, y por otro, el cívico, impuesto por la propia escuela, y por ella recordado. Ambos corresponden a codificaciones diferentes.

En cuanto a la "cuestión religiosa", tenemos que en varios estados de la República mexicana esta tuvo su antecedente en el movimiento de los cristeros. En diversas ocasiones los padres no enviaban a sus hijos a la escuela porque decían que dicha educación "combatía la religión y arrancaba a los hijos del amor de sus padres". Constantemente el gobierno decía que eso era "mentira", que la educación socialista "combatía el fanatismo, capacitaba a los niños para una mejor concepción de sus deberes, para la lucha social y para intervenir como factores en la producción económica". Se enfatizaba en que combatir el fanatismo no quería decir que combatieran las creencias del pueblo, sino que se proponía "destruir los prejuicios que mantenían a la juventud en la ignorancia e impedían el progreso y prosperidad del país" (B. L. A. C., SEP, El Maestro Rural, núm. 6, marzo de 1936).

Esta situación que imperaba en el campo mexicano de los años veinte y treinta, fue la que hizo que, en no pocas ocasiones, la vida cotidiana de los maestros rurales fuera muy difícil. En vano habían puesto sus esperanzas en el movimiento revolucionario y, posteriormente, en la gran jornada educativa desplegada por Vasconcelos. Sus "salarios seguían siendo muy bajos, en ocasiones los recibían con retraso, o bien ni siquiera les llegaban. Y por si esto fuera poco, muchas veces su vida peligraba en ciertas regiones del país" (Entrevista con la maestra Adela Palacios, 1978). 
En la década de los treinta, este problema de la persecusión a los maestros se fue agudizando. Llegó, de este modo, un momento en que muchos maestros tuvieron que abandonar sus cátedras, ya que peligraba su vida. La resistencia de las comunidades se manifestó de manera violenta, y no precisamente en contra del sistema educativo, sino en contra de su emisor, este maestro rural imaginado y creado por las autoridades educativas. Se afirmaba que el problema era más serio de lo que a primera vista pudiera suponerse, ya que varios maestros tanto estatales como federales habían sido "villanamente asesinados" (A. H. SEP, Ref. 244 y 295, 1935).

En algunos pueblos del Bajío de la República mexicana, como en Querétaro, se hablaba de que sus habitantes eran muy "pobres y fanáticos". Se decía que los maestros tenían que hacer entender a los campesinos que las escuelas no eran de "masones ni de protestantes". Así, comentaban, las escuelas federales "luchan por abrirse paso e imponerse por sus cualidades en un medio deliberadamente hostil". De este modo, diversas circunstancias relacionadas con la religión, daban también por resultado el que se atentara en contra de sus vidas (A. H. SEP, ibid.).

Los maestros que prestaban sus servicios en varios estados de nuestro país fueron asesinados por diversas razones. Algunas de ellas se relacionaban con el hecho de que los profesores hacían visitas a varias "negociaciones mineras" en su carácter de "Inspectores Honorarios del Salario Mínimo" y, al aplicar multas en contra de las negociaciones, eran asesinados. En otras ocasiones, sus asesinatos respondían a cuestiones de problemas con la tierra, ya que en México, en la década de los treinta, existían todavía muchos latifundios. De aquí que, en el momento en que los maestros trataban de ayudar para el reparto de las tierras, fueran asesinados (A. H. SEP, Ref. 244, 1935).

La mayor parte de la documentación encontrada entre 1935 y 1936 se refiere a la necesidad de proteger la vida de los maestros rurales. Por otro lado, una de las medidas que se tomaron fue la del cierre, en forma temporal, de los establecimientos educativos que estuvieran "comprendidos en zonas rebeldes" (A. H. SEP, Ref. 295, exp. 2, 1935).

En todas estas comunidades que acabo de presentar nos encontramos con otro imaginario. En estos casos, su imaginario no 
coincidía con el que proponían las autoridades educativas. Sin embargo, no en todos los estados fue igual. Hay otras regiones del país. A manera de ejemplo podemos hablar del estado de Puebla, donde Mary Kay Vaughan encontró que más que una imposición del estado hacia las comunidades, existe una serie de negociaciones, resistencias pasivas o activas, usos selectivos, conflictos y prácticas cotidianas que alteraron la iniciativa gubernamental y le dieron múltiples significados (cfr. Galván y Quintanilla, 1993).

Diversos estudios de historia de la educación regional nos llevan a plantear el hecho de que hubo maestros que lograron superar aquellos problemas de su vida diaria en la comunidad, y pudieron entonces manipular diversas situaciones tanto con los padres de familia, como con los alumnos y con las autoridades locales. Algunos de ellos instrumentaron medidas de acercamiento con la comunidad por medio de visitas a las casas, o bien al utilizar a la escuela como espacio para las reuniones del pueblo. Era en la escuela donde muchos adultos no solo aprendían a leer y a escribir, sino que también se discutían ahí problemas comunes a todos sus habitantes y la forma de resolverlos. Entre otros, el maestro Alfonso Ramírez mencionaba "la falta de agua, de luz, de drenaje y de diversos servicios que cada vez eran más necesarios" (Entrevista con el maestro Alfonso Ramírez, 1977).

Otros maestros, en cambio, optaban por atraer más niños a la escuela y así aumentar su asistencia. Para ello "inventaban" varias formas. Una de ellas era la de la flexibilidad en el horario escolar, con objeto de que este no interviniera en las labores del campo. Es por esto que algunos habían decidido que la escuela se abriera de las 6:00 a las 10:00 horas; vendría después un largo receso donde niños y niñas podrían ir al campo a ayudar a sus padres, o bien a su casa a ayudar en las diversas artesanías y, después, la escuela reiniciaría sus trabajos de 15:00 a 17:00 horas, para evitar así que se hiciera de noche. Sin embargo, estos intentos, que de hecho ya habían sido experimentados por varios maestros durante el porfiriato, muchas veces chocaban con las visitas de los inspectores, quienes en muchas ocasiones, no estaban de acuerdo con estos cambios en el horario escolar (A. H. SEP, Ref. 298, exp. 6, 1935). 
En su intento por adaptarse a la comunidad y ser aceptados, varios maestros lo que hacían era crear todo un sistema de premios para los niños que asistían puntualmente a clases. De este modo, había desde dulces y chocolates, hasta bellos libros para los "niños más aplicados". Este sistema formaba parte de una idea que se venía desarrollando en algunos estados desde finales del siglo XIX cuando se decía que era mejor "premiar que castigar". Los castigos, comenta la maestra Chávez, "fueron perdiendo espacio al ser reemplazados por los premios" (Entrevista con la maestra Ma. de los Angeles Chávez, 1979).

La documentación encontrada y las entrevistas realizadas permiten asomarnos a otras épocas, a otros momentos, a otros imaginarios; permiten comprender cuál era la situación de las maestras y los maestros en el tiempo...

\section{UNA ÚLTIMA REFLEXIÓN}

Una investigación a través del tiempo nos permite ubicar a las maestras y maestros en diferentes momentos. El primero es el del porfiriato, que es cuando se va delineando, de manera más clara, lo que será el imaginario de la maestra y del maestro. Sin embargo, su realidad estaba muy alejada de este imaginario, de aquí que algunos se rebelaran.

Esta es otra cara del magisterio, la de la maestra y el maestro contestatario que no estaba de acuerdo con el régimen porfirista y que, después de muchos ańos de haberlo aceptado en silencio, se levantó en contra del mismo, a pesar de haber sido formado dentro de la ideología porfirista.

Maestras y maestros marginados del régimen, a quienes el tiempo los llevó por otros caminos, muy diferentes de aquellos que los profesores habían escogido cuando decidieron ser preceptores.

La Revolución no trajo tiempos mejores para el magisterio, ya que a pesar de todos sus sacrificios, no obtuvo lo que tanto deseaba. Sus imaginarios de nuevo se vieron frustrados, y terminaba así la década de 1910 participando en un movimiento de huelga.

La maestra y el maestro de "primeras letras" o de "primaria" es un actor muy importante en el análisis del sistema educativo. 
El abordarlo desde dos niveles: el del discurso y el de su vida cotidiana, nos brinda la posibilidad de asomarnos al mundo de la política educativa y al de la educación en épocas remotas. Permite asomarnos a dos imaginarios: el oficial y el de las comunidades. Ambos imaginarios, construidos en tiempos diferentes, se confrontan, se asimilan o rechazan al interior de la escuela.

Considero que, cuando hubo rechazo, se debió a que se trataba de un discurso construido desde la cúpula, imaginado a partir de los intereses de aquellos que manejaban la política. En ningún momento se les ocurría preguntarse por las necesidades que tenían las comunidades a donde iba dirigida esa educación. Más bien se trabaja desde la idea de comunidades imaginadas, pero no reales.

El desconocimiento de muchas comunidades en todo el país, las cuales tienen detrás toda una cultura ancestral, fue lo que trajo como consecuencia la resistencia de muchas de ellas a aceptar esa educación que venía de fuera, que les era extraña, que era imaginada por personas ajenas a su comunidad. Se trataba de comunidades ancestrales, con todo un bagaje cultural. De aquí que se pueda hablar, entonces, de un enfrentamiento entre dos culturas, entre dos tiempos, entre dos imaginarios... Por un lado el imaginario del gobierno central, y por el otro, el imaginario de la cultura ancestral.

En las comunidades donde hubo un rechazo al maestro que había sido imaginado, inventado desde fuera, se dio el ausentismo escolar y el ataque a los propios docentes. Es posible que muchos de los elementos que enseñaba la escuela rural mexicana, los campesinos los sintieran como un atentado a su propia cultura, de aquí la resistencia para enviar a sus hijos a los planteles escolares. Lo que enseñaba la escuela estaba muy alejado de sus ideales, de su vida cotidiana.

Algunos padres de familia lo único que esperaban de la escuela era que sus hijos aprendieran a leer, a escribir y a "hacer cuentas". En el momento en que lo lograban su "tiempo" en la escuela había terminado. Es por esto que encontramos una gran deserción escolar en el periodo de esta investigación.

Dentro del discurso, la cultura que difundía la escuela rural se imaginaba como una panacea que acabaría con vicios y problemas 
ancestrales, y ayudaría para que nuestra nación progresara. Sin embargo, muchos de sus elementos atentaban en contra de una cultura de varios siglos, con raíces muy profundas en su pasado, en sus valores, en todo aquello que era importante para la comunidad.

Queda claro que no todas las comunidades en la República mexicana estaban preparadas para aceptar esta "revolución cultural" que pretendía llevar a cabo la escuela rural. De aquí que solo en algunos lugares se comprendiera el beneficio que se obtendría. De hecho, en varios estudios regionales se habla acerca de cómo las comunidades solicitaban maestros y escuelas. O bien, de qué forma los maestros lograron "negociar" con las comunidades, desde horarios, hasta sistemas de estudio.

Por otro lado, esta aceptación o rechazo no solo dependía de la comunidad y de sus autoridades, sino también de los maestros, algunos de ellos preparados para llevar a cabo esta gran "revolución cultural", pero muchos otros con grandes carencias.

La documentación hasta ahora revisada nos muestra que faltaba mucho por hacer en las comunidades, pero también faltaba mucho por hacer con los maestros. Se trataba de personas imaginadas de acuerdo con los intereses de la política educativa de ese momento. Sin embargo, su preparación académica era muy deficiente. A ellos se les daba una gran responsabilidad, la de difundir la "cultura nacional" y no solo al interior del aula, sino en la vida cotidiana de las comunidades.

El maestro quedará en medio de una gran disyuntiva donde, por un lado, se encontrarán las autoridades y, por otro, la propia comunidad. Las autoridades exigían que el maestro cumpliera con el discurso oficial, y la comunidad se resistía, de diversas maneras, a aceptar ese discurso oficial, a aceptar la cultura de la escuela, a aceptar otros imaginarios.

En muchas ocasiones era en el maestro, y no en el sistema educativo, donde la comunidad identificaba al enemigo, a la persona que atentaba en contra de sus valores, en contra de su cultura. De aquí que, en los años treinta, nos encontremos con maestros asesinados en varias regiones del país.

Esta riqueza documental me ha permitido descubrir a aquel maestro que asistía a diario a impartir sus clases: enseñaba la lectura, las primeras letras y la aritmética, además del trabajo que 
tenía que desarrollar en la comunidad, sobre todo a partir del periodo postrevolucionario. Pude encontrar, así, a aquel maestro marginado de la historia, pero no por ello poco importante.

Considero que este es, precisamente, el maestro que construyó el México que nació después del movimiento revolucionario. Fue este maestro "imaginario" quien, a pesar de todas las dificultades, formó a muchos mexicanos que han participado en la construcción de nuestro país.

\section{ENTREVISTAS A MAESTRAS Y MAESTROS}

Blackaller, Francisca. La entrevisté en su casa el 12 de febrero de 1979.

Cortinas Blackaller, Alicia. La entrevisté en su casa el 9 de enero de 1979.

Chávez, Ma. de los Angeles. La entrevisté en su casa, el 15 de enero de 1979.

Martínez Murillo, Pedro. Lo entrevisté en su casa el 28 de noviembre de 1978.

Palacios de Ramos, Adela. La entrevisté en su casa el 7 de noviembre de 1978.

Ramírez, Alfonso. Lo entrevisté en su oficina de la SEP el 10 de octubre de 1977.

Robles, Juan. Lo entrevisté en la oficina de alfabetización el 15 de noviembre de 1978.

\section{ARCHIVOS Y COLECCIONES}

Archivo Histórico de la Secretaría de Educación Pública. Material citado en el texto con las siglas A. H. SEP.

Archivo Personal E. D. Turner. Blas Lara Césares: Historia de un retrato. Profesora Mariana Gómez, 15 de agosto de 1955.

Colección Porfirio Díaz. Material citado en el texto con las siglas C. P. D.

Colección Latinoamericana Nettie Lee Benson de la Biblioteca de la Universidad de Texas en Austin. Material citado en 
el texto con las siglas B. L. A. C. (Benson, Latin American Collection).

\section{REFERENCIAS BIBLIOGRÁFICAS}

Bazant, Mílada. "La República Restaurada y el Porfiriato", en Francisco Arce et al., Historia de las profesiones en México, México, SEP, El Colegio de México, 1982.

Cockroft, James D. "El maestro de primaria en la Revolución mexicana", en Historia mexicana, vol. XVI, núm. 4, 1967, pp. 565-587.

Constantino Blancas, Cinosura. Presencia de la Escuela Nacional de Maestros en la Historia de México, México, Taller de Artes Gráficas de la ENM,1971.

Diario de Debates. Diario de los Debates de Senadores, 14 de mayo, 1917.

El Escolar Mexicano. Semanario de instrucción, moral y recreo, dedicado a la niñez y profesorado de instrucción primaria, México, Publicación de la Dirección General de Instrucción Primaria, 1889.

Galván, Luz Elena. "Papel del maestro durante el porfiriato", en Simposio sobre el Magisterio Nacional, vol. I, México, CISINAH, 1980.

Galván, Luz Elena. Los maestros de ayer: un estudio histórico sobre el magisterio (1877-40), México, CIESAS, 1981.

Galván, Luz Elena. El proyecto de educación pública de José Vasconcelos, México, CIESAS, 1982.

Galván, Luz Elena. Los maestros y la educación pública en México. Un estudio histórico, México, CIESAS, 1985.

Galván, Luz Elena. La educación superior de la mujer en México: 1876-1940, México, CIESAS, 1985.

Galván, Luz Elena. Soledad compartida. Una historia de maestros: 1908-1910, México, CIESAS, 1991.

Galván, Luz Elena. "Profesores en el movimiento de 1910-1917”, en Hojas, año 1, núm. 6, agosto, 1992, pp.18-23. 
Galván Luz Elena y Susana Quintanilla. "Historiografía de la educación", en 2o. Congreso de Investigación Educativa, México, SEP-CONACyT, 1993.

González y González, Luis. Pueblo en vilo, México, Fondo de Cultura Económica, SEP, 1984.

González Navarro, Moisés. "El Porfiriato. La vida social”, en Cosío Villegas, Historia Moderna de México, México, Buenos Aires, Hermes, vols. I-IV, 1957.

Le Goff, Jacques y Antonio Santoni. Investigación y enseñanza de la historia, trad. del italiano de Ma. Esther Aguirre Lora, Editor de la versión italiana, Luciano Manzuoli, 1988 (en prensa).

Llinás Álvarez, Edgar. Revolución, educación y mexicanidad. La buisqueda de la identidad nacional en el pensamiento educativo mexicano, México, UNAM, 1978.

Mendieta Alatorre, Ángeles. La mujer en la Revolución mexicana, México, Instituto Nacional de Estudios Históricos de la Revolución Mexicana, 1961.

Murillo Reveles, José Antonio. "La escuela mexicana. Su génesis, su doctrina y su sistema”, s/e, Zacatecas, México, 1949.

Naranjo, Francisco. Diccionario biográfico revolucionario, México, Imprenta Ed. Cosmos, 1935.

Pani, Alberto. Una encuesta sobre educación popular, Departamento de Aprovisionamientos Generales, México, 1918.

Patlagean, Evelyne. "La historia de lo imaginario", en Le Goff, La Nueva Historia. Diccionarios del Saber Moderno, Bilbao, España, Ed. Mensajero,1988.

Prieto, Guillermo. Viaje a los Estados Unidos por Fidel, 2 vols. México, Imprenta del C. de D. y Chávez, 1878.

Quiroz, Alberto. Biografías de educadores mexicanos, México, SEP, 1962.

Sáenz Royo, Artemisa. Semblanzas. Mujeres mexicanas, México, Imprenta M. León, 1960.

Secretaría de Educación Pública. Las Misiones Culturales en 1927. Las Escuelas Normales Rurales, México, Publicaciones de la SEP, 1928.

Sierra, Justo. Epistolario y papeles privados. Edición establecida por Catalina Sierra de Peimbert, México, UNAM, 1949. 
Staples, Anne. "Alfabeto y catecismo: salvación del nuevo país", en La educación en la historia de México, México, El Colegio de México, 1992.

Tannenbaum, Frank. "México, la lucha por la paz y por el pan", en Problemas agrícolas e industriales de México, México, s/e, 1949.

Vasconcelos, José. El Desastre, México, Editorial Botas, 1938. 